\title{
The Quiet Leader
}

\author{
Jason E. Cheng ${ }^{1}$
}

Received: 17 July 2021 / Accepted: 3 September 2021 / Published online: 28 September 2021

(c) Academic Psychiatry 2021

"Why are you so quiet?" asked one of the popular girls. "I don't know," I said, and did not know what else to say. It is one of my strongest memories from elementary school, perhaps because it encapsulates a core struggle. Fast forward to my third year of medical school, which was exhausting as I struggled with the volume and intensity of the work.

My natural inclination in groups is to come up with reasons why I should not speak up. During the pandemic, I was on a Zoom meeting with forty-some people and felt hot as I struggled to find a time to gently put in my two cents. Psychiatry was attractive to me due to the promise of understanding what makes people tick, including myself. I had lots of questions. At the beginning of residency, my entire intern class did a professional personality assessment, and I was the most introverted. Later on, in a weekly process group whose purpose was to teach us about group dynamics, one of my classmates called me out for not talking more. Is it my personality?

As a resident advisor in a college dorm, I was drawn to programming on diversity and culture. I wanted to understand my own Asian culture and the consequences of differences from other cultures. During both medical school and residency, I worked on cultural curricula. My residency rank list took into account strength of cultural psychiatry training, and I chose a program that had an Asian Focus inpatient unit with bilingual and bicultural staff. In my PGY-4 year, I did an elective at a clinic in the local Chinatown. One of my coresidents joked that I was doing an Asian Focus residency. Asians are stereotyped to be quiet and deferential [1]. There is a Chinese proverb that can be translated to "the shot hits the bird that pokes its head out." So is it my culture?

Part of the stress of being a minority is the challenge of distinguishing between what is of my culture and what is of my personality. Or does it matter? I had a psychotherapist who did not bring up my culture in her interpretations. When

Jason E. Cheng

chengj@mmc.edu

1 Meharry Medical College, Nashville, TN, USA
I pointed that out, she protested and told me to look at the books on culture on her shelf. For me, though, it was not academic. My father had strict expectations. He approved of my initial path that led to a bachelor's degree in engineering, but I was also premed early in college. I do not remember him telling me to do medicine, though I knew it was something he would approve. After all, his own father had wanted him to be a doctor. My father told me I should go into surgery rather than psychiatry. His focus was salary, and stigma against mental health issues played a role as well. How much of my journey to be a physician is for familial or cultural reasons, and how much of it was for myself?

I now know that the personal and cultural mix. The human mind is complex, often with multifactorial origins and causes of thoughts, feelings, and behaviors. A study found that Asian and underrepresented minority medical students had higher levels of reticence [2]. My culture and personality have led my phenotype to match Asian stereotypes, resulting in some of my challenges in education and applications. However, characteristics that are more common in certain cultures can be found in people of other cultures, and some people do not fit the stereotype of their cultures. I met an Asian medical student who was nothing if not outspoken but got feedback that she was too quiet. She was seen as a stereotype rather than as a person.

Furthermore, a growing body of research is demonstrating that Asian students are held to higher standards than others in areas such as undergraduate applications and in medicine, Alpha Omega Alpha Honor Medical Society membership [1]. Though Asians do well in many measures of success in the United States, the "bamboo ceiling" causes Asians to be underrepresented in leadership roles relative to their proportion of junior positions in the fields of tech and law [3]. In medicine in general and in psychiatry specifically, the percentage of full professors who are Asian is below the percentage of more junior faculty who are $[4,5]$. Also in medicine, Asians may lag behind even underrepresented minorities in higher administration positions [1].

The three youngest members of my residency process group, including myself, were the quietest. I can only speak 
for myself that my limited life experience at the time made me more reserved, and that with more experience I have grown more comfortable speaking up. During fellowship, my faculty preceptor pointed out that I seemed reticent to participate in class at times. I told her that when I won a resident leadership award, one faculty member told me that I was quiet but got things done. "The quiet leader," my preceptor remarked. "That would make a good paper." After being a clinical administrator and then a residency program director, I have partial answers to some of my early questions. I still find it challenging to speak up at times, but since these roles have involved frequent public speaking, I just do it. While I am not a natural leader, I have gone outside my comfort zone time after time to take on more leadership roles.

Whether I am quiet because of my culture, my personality, or both, sometimes it means I am a good listener and think a lot before speaking, which is helpful in certain situations. With our leadership team including our department chair and chief residents, different members connect better with different people and are naturals in different scenarios, which can be mediated by personality or culture. Therefore, our differences in these areas allow us to better handle anything that comes up. If we encourage people of different personalities and cultures to contribute as leaders in medicine, we will be stronger for it.
Acknowledgements The author wishes to acknowledge Dr. Lloyda Williamson and dedicate this article to the memory of Dr. Sara Kellermann. Both provided encouragement in writing about one of the themes of this paper.

\section{Declarations}

Disclosures The author states that there is no conflict of interest.

\section{References}

1. Ko M, Ton H. The not underrepresented minorities: Asian Americans, diversity, and admissions. Acad Med. 2020;95(2):184-9.

2. Lee KB, Vaishnavi SN, Lau SK, Andriole DA, Jeffe DB. "Making the grade:" noncognitive predictors of medical students' clinical clerkship grades. J Natl Med Assoc. 2007;99(10):1138-50.

3. Lu JG, Nisbett RE, Morris MW. Why East Asians but not South Asians are underrepresented in leadership positions in the United States. Proc Natl Acad Sci U S A. 2020;117(9):4590-600.

4. U.S. Medical School Faculty by Rank and Race/Ethnicity, 2020. Association of American Medical Colleges. 2020. https://www. aamc.org/media/8906/download. Accessed 14 Aug 2021

5. Chaudhary AMD, Naveed S, Siddiqi J, Mahmood A, Khosa F. US psychiatry faculty: academic rank, gender and racial profile. Acad Psychiatry. 2020;44(3):260-6.

Publisher's Note Springer Nature remains neutral with regard to jurisdictional claims in published maps and institutional affiliations. 